2016;91:652-654.

3. Rallis E, Stavropoulou E, Paraskevopoulos I. Nimesulide-induced, multifocal, urticarial fixed drug eruption confirmed by oral provocation test. Indian J Dermatol Venereol Leprol. 2008;74:403-4.

4. Sarkar R, Kaur C, Kanwar AJ. Extensive fixed drug eruption to nimesulide with cross-sensitivity to sulfonamides in a child. Pediatr Dermatol. 2002:19:553-4.

5. Kumaran S, Sandhu K, Saikia UN, Handa S. Nimesulide induced bullous fixed drug eruption of the labial mucosa. Indian J Dermatol Venereol Leprol. 2004;70:44-5.

Lidiane Pereira Marques

Ana Luiza Castro Fernandes

Villarinho

Maria das Graças Mota Melo

Marília Gabriela Senra Torre

How to cite this article: Marques LP, Villarinho ALCF, Melo MGM, Torre MGS. Fixed drug eruption to nimesulide: an exuberant presentation confirmed by patch testing. An Bras Dermatol. 2017;93(3):470-2.

\section{Extradigital glomus tumor mimicking osteomuscular disease*}

\section{DOI: http:/ /dx.doi.org/10.1590/abd1806-4841.20187559}

Bruno de Castro e Souza ${ }^{1}$

Maria Cláudia Alves Luce ${ }^{1}$

José Alexandre de Souza Sittart ${ }^{1}$

Neusa Yuriko Sakai Valente ${ }^{1}$

\section{Dear Editor,}

We present a case of glomus tumor located on the lower third of the right thigh in a patient who presented with pain in the knee region for many years. Investigation for osteomuscular disorders was not successful.

A 50-year-old man sought dermatological consultation reporting an intense, episodic shooting pain in the right knee for 4.5

\footnotetext{
Received 21 August 2017.

Accepted 13 October 2017

* Work conducted at Hospital do Servidor Público Estadual de São Paulo, São Paulo (SP), Brazil.

Financial support: None.

Conflict of interest: None.

Department of Dermatology, Hospital do Servidor Público Estadual de São Paulo, São Paulo (SP), Brazil.
}

MAILING ADDRESS:

Bruno de Castro e Souza

E-mail: brunocastro1990@hotmail.com

(C2018 by Anais Brasileiros de Dermatologia

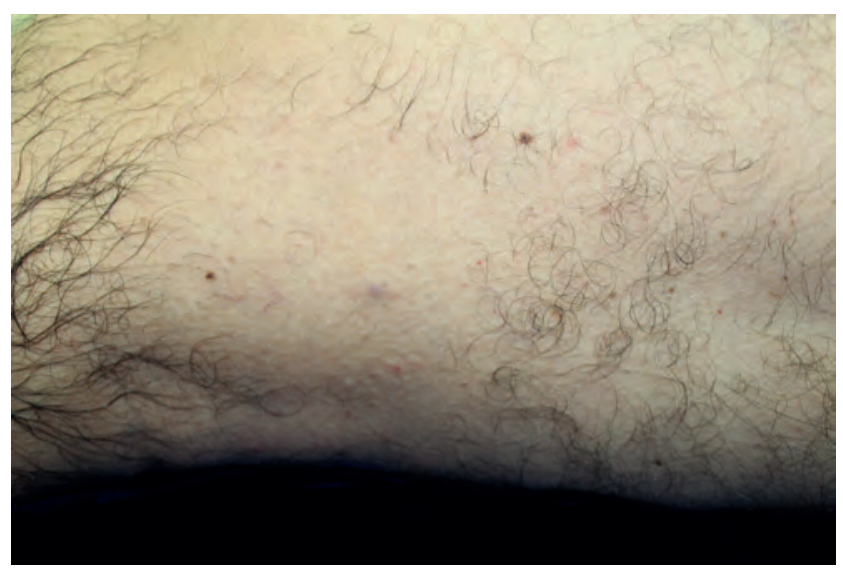

Figure 1: Violaceous papule on the left thigh

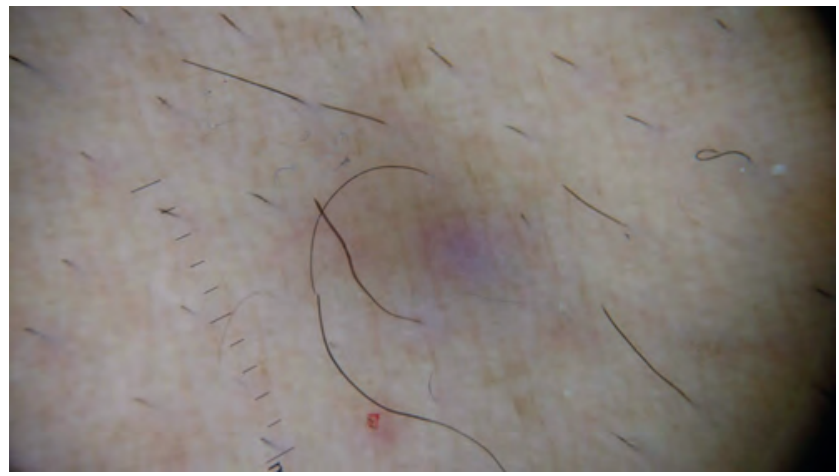

FIGURE 2: Non-contact polarized dermoscopy showing a violaceous, homogeneous, structureless and patternless lesion

years, that worsened with movement or mild touch, including with simple touch of clothes. He denied worsening with cold. He had seen many orthopedists with such complaint and underwent multiple imaging studies, among them 5 nuclear magnetic resonance (NMR) and 3 ultrasounds (US) of the knee and lower third of the right thigh. In only one US, a small subcutaneous nodule on the left thigh was described, however, such finding was not taken into consideration by the physicians then. The tumor was not described in any of the reports from NMR. In view of the undefined diagnosis, he still underwent electroneuromyography, which did not show any abnormalities.

The osteomuscular examination did not reveal edema, heat or crackling of the knee. Dermatological examination revealed a violaceous papule, measuring $4 \mathrm{~mm}$, close to the femur lateral condyle, which triggered a sharp pain upon minimal contact (Figure 1). Non-contact dermoscopic examination with polarized light showed a violaceous, homogeneous lesion with no structures or patterns (Figure 2). Because of the clinical aspect and peculiar symptoms, we raised the hypothesis of extradigital glomus tumor and proceed to surgical excision.

Histopathology revealed a proliferation of blood vessels 


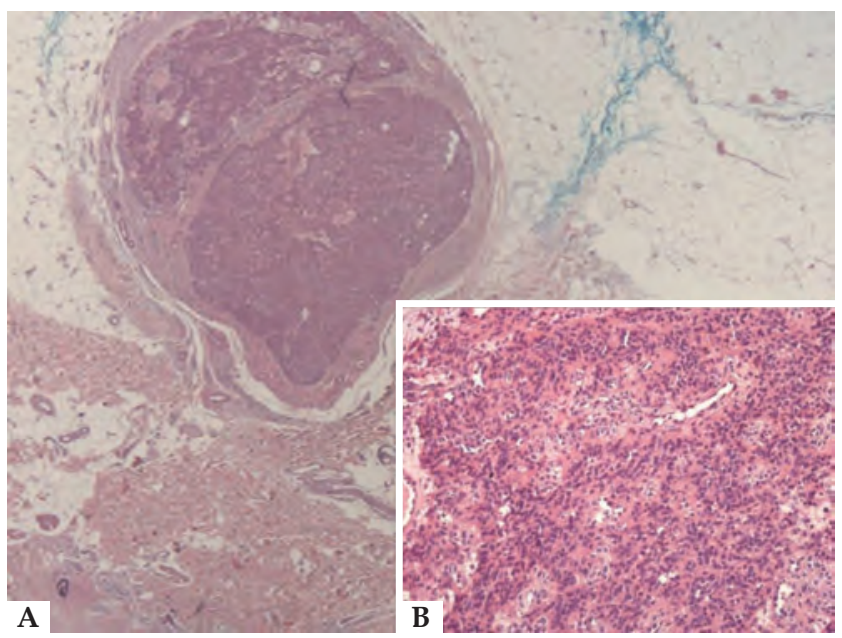

Figure 3: A - Encapsulated neoplasia in the subcutaneous tissue (Hematoxylin \& eosin, X20). B - Benign neoplasia formed by cuboidal, uniform cells around vessels (Hematoxylin \& eosin, X200)

surrounded by small, uniform cells with round or oval-shaped nuclei (glomus cells), typical findings of glomus tumor (Figure 3). Resection margins were free. The patient came for follow-up after 2 months and was completely asymptomatic.

Glomus tumor is considered a rare, benign neoplasia, that corresponds to approximately $1.6 \%$ of the soft tissue tumors located on the extremities. ${ }^{1}$ it arises from the glomus bodies, neuromyoarterial structures in the skin that function as specialized arteriovenous anastomoses, aiding in the regulation of body temperature and blood flow. These structures are found all over the skin, but are more concentrated in the extremities, what explains the higher involvement of the subungual region by the tumor. ${ }^{2}$ Glomus tumor is equally prevalent in both genders, however, the "ectopic" locations are more common in men. ${ }^{1}$ Clinically, it presents as a firm, purple-blue, usually single nodule, with the classic triad of pain, hyperesthesia on palpation and cold sensitivity (worsening of the pain when exposed to the cold). ${ }^{2,3}$ When its location is extradigital, it frequently becomes a diagnostic challenge, because many times it does not present with the classical clinical picture. Schiefer et al., in a study on extradigital glomus tumors, found $86 \%$ of localized pain and heat and only $1 \%$ of cold insensitivity, such as in the presented case (the patient denied worsening with the cold). ${ }^{3}$ Our patient had a lesion on an unusual site, close to the knee, what led him to different orthopedists, who also interpreted his complaints as osteomuscular in nature and recommended treatment with physiotherapy. This professional was the one who referred to a dermatology consultation.

There are few reports of glomus tumors mimicking joint disorders. Especifically on the knee, the tumor was already described in the subcutaneous tissue, in the patellar ligament and even in an intra-articular location. Since the differential diagnosis for knee pain is broad, when this neoplasia is present the diagnosis is rarely made, and it can take up to 40 years after the onset of symptoms. ${ }^{4}$
The diagnosis is suggested by the clinical presentation, since dermoscopy is non-specific. The findings described include homogeneous white structure with peripheral telangiectasias or structureless violaceous areas, as in our case. ${ }^{5}$ Imaging tests can also help in the diagnosis, being the NRM the most sensitive ( $82 \%$ to $90 \%$ ), detecting lesions with a diameter smaller than $2 \mathrm{~mm} ., 3$ We assume that the lesion was not detected in our patient with the NRM because the complaint was of pain in the joint, so the radiologists did not recognize it either. Histology confirms the diagnosis, showing a tumor enveloped by a fibrous capsule, with vascular spaces surrounded by glomus cells (eosinophilic cytoplasm and oval or cuboidal nucleus). ${ }^{1}$

After surgical excision, there is complete regression of symptoms and low recurrence rates. ${ }^{2}$

We alert to the fact that painful skin and subcutaneous tissue tumors can mimic osteomuscular conditions, especially when the location is juxta-articular. $\square$

\section{REFERENCES}

1. Clark ML, O'Hara C, Dobson PJ, Smith AL. Glomus tumor and knee pain: A report of four cases. Knee. 2009;16:231-4.

2. Chou T, Pan SC, Shieh SJ, Lee JW, Chiu HY, Ho CL.. Glomus Tumor - Twenty-Year Experience and Literature Review. Ann Plast Surg. 2016;76:S35-40.

3. Schiefer TK, Parker WL, Anakwenze OA, Amadio PC, Inwards CY, Spinner RJ. Extragenital glomus tumors: A 20-Year Experience. Mayo Clin Proc. 2006;81:1337-44.

4. Drosos $\mathrm{Gl}$, Ververidis A, Giatromanolaki A. Glomus tumor as a rare cause of anterior knee pain. J Med Cases. 2015;6:36-9.

5. Oliveira A. Dermoscopy un the diagnosis of extradigital glomus tumor. Int $J$ Dermatol. 2016;55:e506-8.

$\begin{array}{ll}\text { Bruno de Castro e Souza } & \text { (D) ORCID 0000-0001-7140-3462 } \\ \text { Maria Cláudia Alves Luce } & \text { (D) ORCID 0000-0002-1464-0821 } \\ \text { José Alexandre de Souza Sittart } & \text { (iD) ORCID 0000-0001-5267-9930 } \\ \text { Neusa Yuriko Sakai Valente } & \text { (iD) ORCID 0000-0002-8065-2695 }\end{array}$

How to cite this article: Souza BC, Luce MCA, Sittart JAS, Valente NYS. Extradigital glomus tumor mimicking osteomuscular disease. An Bras Dermatol. 2018:93(3):472-3. 